\title{
Additive Manufacturing Concepts and Design for Advanced Composites Materials
}

\author{
Besnea Daniel, Victor Constantin, Octavian Dontu, Spanu Alina, and Doina Cioboată
}

\begin{abstract}
The paper presents the development of the technology based on solid state material deposition used for obtaining new composite material such PLA (polylactic) and graphite nanotubes having specific mechanical properties. The advantage of the process are the direct manufacturing of the functional parts with the verification and approval of their mechanical properties and the indirect utilizable new composite material with FDM (Fused Deposition Material).
\end{abstract}

Index Terms-Composite materials, manufacturing for prototype, nanotubes as master model for new flexible tools for steel part manufacturing for prototype or small series production.

\section{INTRODUCTION}

The new manufacturing technologies such as Additive Manufacturing (AM) were a crucial step for technological research and development at the beginning of the $90^{\mathrm{s}}$.The new AM technologies are the result of thorough researches and progress achieved in various fields: from precision engineering to numerical control, from laser technologies to three-dimensional modeling, from IT fields to the material sciences. The rapid prototyping technologies afford a large flexibility for carrying them out, which is an advantage for manufacturing some micro-components with high dimensional accuracy used as models of functional conceptions / prototypes, or for reverse using as master models for manufacturing some flexible devices for metal parts for single or small series production [1], [2].

The proposed article is about the deep study of theoretical aspects regarding the additive manufacturing (FDM - Fused Deposition Modeling) and finding new solutions for resolving the problems regarding AM as a very important demanding. From its content, the aim of the article is the development of additive manufacturing technology as a solid state and the obtaining new composite materials for deposition (PLA and nanotubes) and the obtaining of new conceptual models and functional prototypes with properties and superior mechanical characteristics.

Nanotechnology is a new technological field that opens huge future directions, at least for developing new materials, and a large nanotechnology researches are focused on carbon

Manuscript received April 27, 2017; revised July 30, 2017

Besnea Daniel, Constantin Victor, Dontu Octavian, and Spanu Alina are with the Politehnica University of Bucharest, Bucharest, Romania (e-mail: d_bes@yahoo.com, octavdontu@yahoo.com,spanu_alina@yahoo.com).

Doina Cioboată is with the National Institute of Research and Development in Mechatronics and Measurement Technique, Bucharest, Romania (e-mail: cioboatadoina@yahoo.com). nanotubes. Carbon nanotubes are microscopic structures which seem with the graphite-a thin layer of atoms following a pattern as honey comb. They were considered a wonder material from the beginning of their existence in earlier 90s. The carbon nanotubes have electrical, mechanical and thermal distinct properties: high electrical conductivity, which could be thousand times greater than that of copper, hardness almost equal with that of the diamante, mechanical resistant almost fourteen times greater than that of Kevlar. The researches have proved that carbon nanowires are materials with very great resistance for shocks. Usually there are used PLA (polylactic) materials in rapid prototyping technologies that is plastic material obtained by processing some vegetables such as corn, sugar, potatoes, without dangerous components for the environment, very resistant and rigid used for the objects which will be kept in conditions of normal temperatures and ABS (Acrylonitrile butadiene styrene), which is a very versatile polymer used in a large number of industries, in $3 \mathrm{D}$ - printing $\mathrm{ABS}$ is a very rigid plastic with high resistance at high temperature (it changes the shape at 100 degrees) and with easier flexibility in comparison with PLA , that is useful for manufacturing the objects requiring the bent, it is soluble in acetone and some different sides of an object could be glued together, being a material used especially by the engineers.

In Fig. 1 is presented the 3D printer that used PLA or ABS as material deposition [3]-[5].

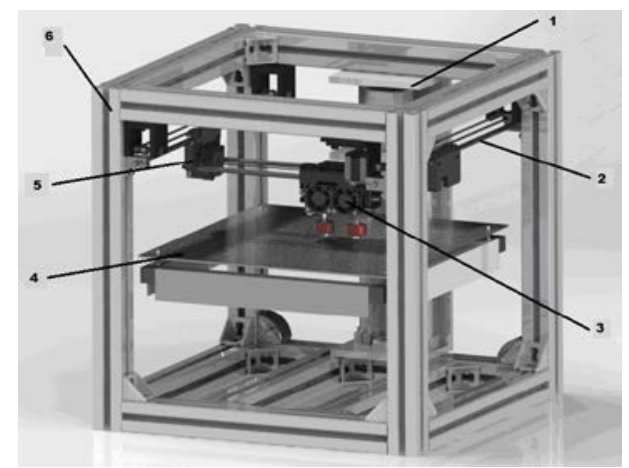

Fig. 1. The CAD model of rapid prototyping system - FDM procedure 1- Z axis; 2 - Y axis, 3 - printing heads, 4 - printing table, 5 - X axis, 6 - metallic frame.

There are various and many fields of using them: mechanical engineering and mechatronics, the automation and computers, electrical engineering, electronics. The new obtained material could be used for limb prosthesis, orthopedics shoes, models for conceptual ideas, functional prototypes and some presentation models for evaluation and improving their external shapes, design including the FEM analysis, even for packaging. 


\section{PRESENTATION OF THE CONCEPT OF TECHNOLOGY}

The processes based on material extrusion uses a wire made of some materials with specific qualities that is warmed up at a temperature which is only few degrees below the melting temperature, and after the diameter is reduced around $0.12-0.15 \mathrm{~mm}$ by its extrusion in a deposition device that is moved along the XOY plane for realizing a section of 3D virtual model. The process known as Fused Deposition Modeling is a manufacturing process site of rapid prototyping (RP) technologies which affords a large flexibility for practice. This advantage could be explored for manufacturing micro-mechanical parts with a very good dimensional accuracy by using CAD files for controlling the computer which drives the equipment.

The key of the procedure is given by the rigorous control of the temperature used for warming the material up and maintaining the temperature during the deposition. The warming of ABS wire is made for temperature of $270^{\circ} \mathrm{C}$, and for PLA is $215^{\circ} \mathrm{C}$, and the material is maintained in a semi liquid state, so that it could be extruded by a nozzle with a very small diameter $(0.254 \mathrm{~mm}$ or $0.127 \mathrm{~mm})$.

The nozzle by which is passing the extruded plastic material with a semi liquid state, could be moved together with the warming head where it is placed, along the XOY plane and the movement is controlled by a computer. The processed part is placed on a platform with movement along the $\mathrm{Z}$ axis, all being numerical controlled by a computer.

The advantages of the process are the direct manufacturing of the functional parts, with the verification and approval of their mechanical properties and the indirect utilizable new composite material with FDM as master model for new flexible tools for steel part manufacturing for prototype or small series production. Other advantages are: the manufacturing process has not much material as waste; the materials have affordable costs; the FDM equipment are easy to use and does not require special conditions for working process. The main disadvantage is given by the quality of the surfaces that are not very well polished due to the scale effect and the low accuracy (0.1-0.2 mm).

Based on the Fused Deposition Modeling process but obtaining a new depositing material by combining common materials (PLA or ABS) with carbon nanotubes, a new filler material is obtained.

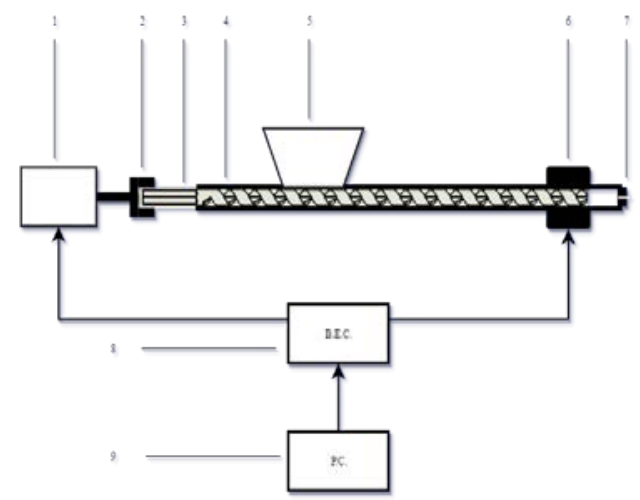

Fig. 2. The schematic of the system for obtaining the composite material $1-$ d.c. motor; 2-coupling; 3 - worm gear; 4 - tube; 5- - vat; 6-resistances and thermistors; 7- nozzle; 8-electronic block control; 9-computer.

The extrusion consist in heating the plastic material as it using the meltable temperature. After that, it is forced to pass through a spinning nozzle with changeable section and reching the wanted shape finally.The thermoplastic materials are chemical polymer substances made of some natural or artificial macromolecules as synthesis result from petrol, coal, natural gases, characterised by specific meltable point. Due to this characteristic, they can be modeled together with carbon nanotubes under the temperature and pressure influences by obtaining a homogenous composition. The mixture is put in the vat and is passing through a cylinder with a worm gear Fig. 2.

Because of homogenous section requiring for the composite material, the main parameters of the process, such as worm gear speed, the temperature inside the cylinder, the speed used for cooling the extruded material, should be controlled accurately Fig. 3.

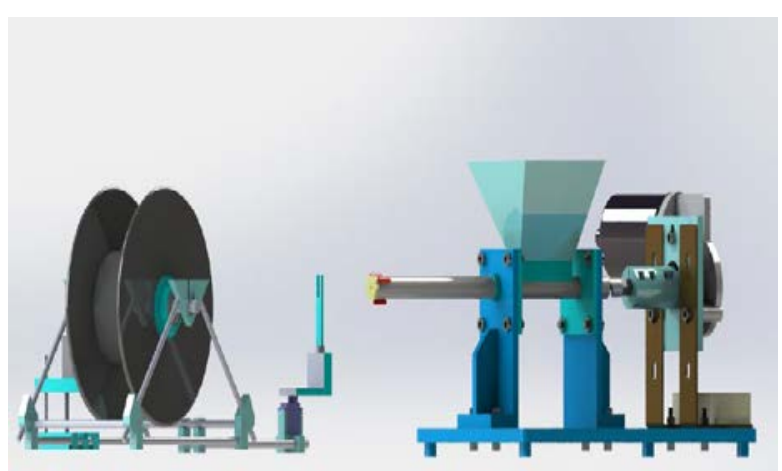

Fig. 3. Extruder and filament roll assembly.

In order to extrude material strict temperature control is needed, so the heaters were positioned on the pipe in pairs, allowing for further testing of the system - testing installation show in Fig. 4.

1) An area to soften the material (PLA) - the target temperature for this stage is 80 degrees $\mathrm{C}$ - mixing with the carbon nanotubes is possible at this temperature.

2) The second area raises the temperature to 180 degrees $C$ the material becomes liquid.

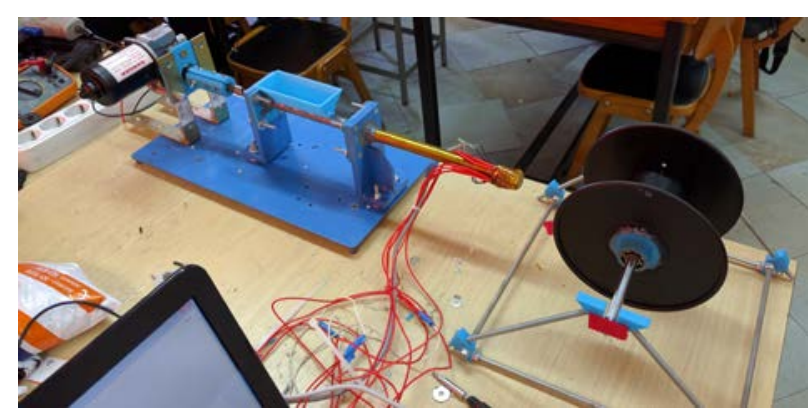

Fig. 4. Experimental installation used for obtaining the material.

Following tests at a speed of 20 RPM of the lead screw with a temperature of 220 degrees $C$ obtained by using the resistors it was observed that the filament is usable for the next step of manufacture.

The manufacturing process using the FDM (Fused Deposition Modeling) system consists of three main stages, namely the preprocessing stage, the actual construction phase of the part and the post processing stage.

During the preprocessing stage, the CAD model of the 
piece is loaded into the QuickSlice specialized program, a program that generates the FDM machine code, where the CAD model orientation in the machine's workspace is made so that the piece construction is optimal from the point of view of Working time and material consumption. After the orientation of the CAD model, it is cut in parallel with the plane of the machine (horizontal planes), operation resulting in several sets of level curves called perimeters. The sectional section along the $\mathrm{Z}$ axis is $0.2 \mathrm{~mm}$, it is chosen according to the diameter of the melt extrusion nozzle, the QuickSlice program generates the paths that the extrusion head must follow in order to materialize a section of the piece, Fig. 5. It generates sets of level curves, and then there is a global analysis of the piece, which leads to the generation of supports for the hanging pieces of the part.

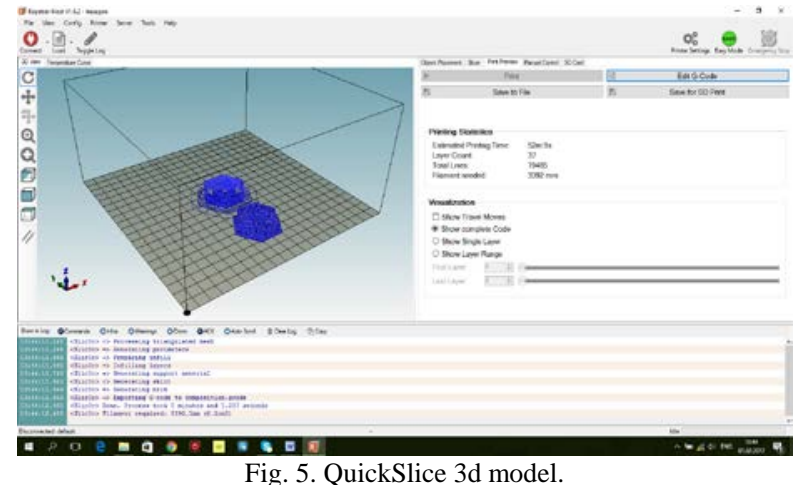

In the stage of construction of the piece, the piece, layer with layer is made, the extrusion heating head of the machine deposits a thin yarn of construction material, with a diameter of $1.75 \mathrm{~mm}$, along the curves defining the perimeter of the section, after the perimeter materialization has Place the construction material in the areas that correspond the filled areas of the work piece.

If necessary, the support material is deposited by the second nozzle of the heating-extrusion head, then after the entire section of the current section is fully materialized, the platform of the car descends with an elevation equal to the virtual model section pitch, and The whole process resumes for a new section until the last section of the virtual model of the piece materializes.

Experimental installation Fig. 6, is provided with two heating heads - extrusion having the following technical characteristics: working volume: $400 \times 400 \times 250 \mathrm{~mm}$;

Connection: USB, Wi-Fi, card reader: SD / MMC; Operating system: Arduino / Repetier-Host.

The system is powered by a Atmel 2560 microcontroller development board and a Ramps 1.4 board with A4988 stepper drivers (X, Y and extrudes), Fig. 6. The Z-axis stepper motor is controlled by a TOSHIBA TB6560-type driver, made by the authors. The system's end-of-travel sensors are of the optic type to reduce hysteresis typical of mechanical sensors.

The two heating elements are controlled in a closed loop by means of two MOSFET transistors and two temperature sensors. The inclusion of the second extruder required changes to allow the control of an additional cooling fan needed to cool the second extruder temperature. Also, the development board firmware has been modified so that with two PID algorithms it is possible to simultaneously heat the heating elements.

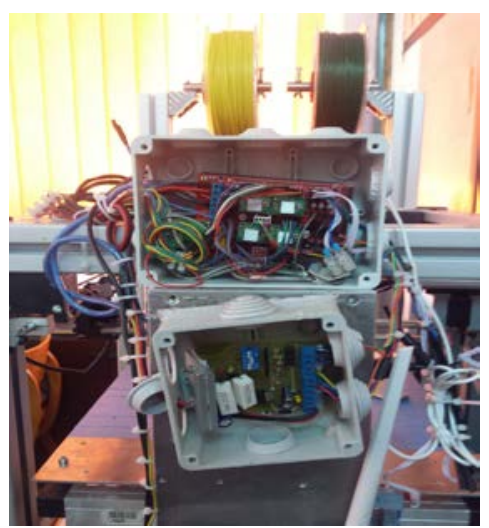

Fig. 6. Microcontroller development board and a Ramps 1.4 board.

The development board is connected via the USB port to a microcomputer with a Debian operating system. It runs an Apache server through which system settings can be accessed or tasks can be established. It is also possible to connect a camera through which the process can be monitored. A large part of the testing was performed using the IoT platform developed in the MUTCAFE project.

The system has been designed as an independent cell - Fig. 7, and is also equipped with a router that allows quick connection via Ethernet or Wi-Fi.

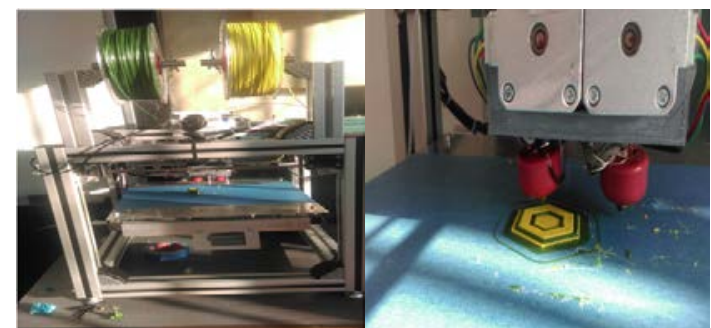

Fig. 7. FDM Experimental model with two heater - extruder heads.

The last post-processing step consists of separating the work platform from the building, removing the connecting element between the actual work piece and the platform, removing the supports (if any) and finishing the work piece if necessary.

The main factors influencing the accuracy of execution of the parts obtained by the FDM process are: the precision of the STL file. Which influences the precision of the piece in that a poor quality of it translated by relatively high deviations from the original CAD model leads to inadequate parts; The orientation of the model in the working space of the machine is important from the point of view of the manufacturing precision of the piece; The diameter of the extrusion nozzle of the material influences the work piece precision by the fact that depending on it, the dimensions of the thread section will result; The step of cutting the virtual model influences the execution precision of the piece by the so-called trapping effect that occurs during the construction process, as the sectioning step of the CAD model is larger, the more the piece will be more imprecise; The complexity of the piece and the fineness of the details if the piece to be built contains elements smaller than the dimensions of the thread of the deposited material, then these details will be lost; The 
type of material used to make the piece influences its machining accuracy, because depending on the material used, the diameter of the extrusion nozzle and the dimensions of the thread section of the deposited material are determined.

\section{CONCLUSION}

The paper presents one of advanced additive technologies, the modeling and computer manufacturing tendencies. There are described some aspects regarding the methods for obtaining new composite materials by pointing out the recent scientific researches for manufacturing some parts with superior functional properties. By improving the material properties, a new field of research is opened for rapid prototyping technology, a new way for testing the conceptual model during a short period with very low costs. The presented system is cheap and could be used without any special demanding. The main problem is the temperature control, so that the mechatronic system is suitable nearby the possibility of controlling the nozzle shape.

This article describes the global trend towards using Rapid Prototyping manufacturing systems for product development or upgrading, these new technologies are capable of producing models or prototypes with acceptable accuracy in a very short time, with major economic benefits. These new technologies, allow for making faster and cheaper products.

\section{ACKNOWLEDGMENT}

This work was supported in part by University Politehnica of Bucharest, through the "Excellence Research Grants" program, UPB - GEX. Identifier: UPB-EXCELENT, Ă-2016 Research project title, Contract number 39/26.09.2016.

\section{REFERENCES}

[1] P. Berce, N. Balc, C. Caizar, R. Pacurar, A. S. Radu, S. Bratean, and I. Fodorean, "Tehnologii de fabricaţie prin adăugare de material şi aplicaţiile lor,” Editura Academiei Romane, Bucureşti, 2014.

[2] P. Berce, N. Balc, M. Ancau, S. Comsa, C. Caizar, and H. Chezan, "Fabricarea rapidă a prototipurilor,” Editura Tehnică, Bucureşti, 2000.

[3] M. M. Popovici, "Modelarea virtuala 3D," construcţia de maşini, Bucureşti, 2005.

[4] D. Besnea, O. Dontu, N. Alexandrescu, G. I. Gheorghe, P. Beca, and A. Abalaru, "Tehnologii de fabricaţie asistate de calculator pentru execuţia unor componente mecatronice,” Editura Printech, Bucureşti, 2008.

[5] D. Besnea, A. Spanu, I. M. Prodea, G. Tomescu, and I. C. Panait, "Optimizarea constructive a dispozitivelor de ametecare de tip elice cu ajutorul metodei de prototipare virtuala si rapida,” Revista de Chimie, vol. 68, no. 3, pp. 453-458.
Daniel Besnea was born in Buzau, Romania, on July 19, 1967. He graduated from Politechnica University of Bucharest, Faculty of Fine Mechanics and Doctoral School of Faculty of Mechanical Engineering and Mechatronics, receiving the $\mathrm{PhD}$ engineer. Eng. degree.

He published: Tehnologii de fabricatie asistate de calculator, editor Printech, Bucharest in 2008; Utilizarea aplicatiilor de tip CAD, editor CD Press, Bucuresti in 2007; Metrologie si controls dimensional, editor Academiei Oamenilor de Stiinta din Romania, Bucharest in 2011.

Dr. Daniel Besnea is a member of SROMECA (Romanian Society of Mechatronics) and a member of The Romanian Robotics Society.

Victor Constantin was born in Bucharest, Romania, on June 17, 1980. He graduated from Politechnica University of Bucharest, Faculty of Fine Mechanics and Doctoral School of Faculty of Mechanical Engineering and Mechatronics, receiving the $\mathrm{PhD}$ engineer. Eng. degree.

He published: Utilizarea aplicatiilor de tip CAD, editor of CD Press, Bucharest in 2007. Dr. Victor Constantin is a member of SROMECA (Romanian Society of Mechatronics) and a member of The Romanian Robotics Society.

Octavian Dontu was born in Campina, Romania, on February 26, 1947. He graduated from Politechnica University of Bucharest, Section of Fine Mechanics and Doctoral School of Faculty of Mechanical Engineering, receiving the $\mathrm{PhD}$ engineer. Eng. degree.

He published: Masini si sisteme integrate de fabricatie, editor Printech, Bucharest in 2015, Metode si mijloace pentru evaluarea gradului de poluare a aerului ai apei marine, editor Printech, Bucharest in 2009.

Prof. Octavian Dontu Constantin is a member of SROMECA (Romanian Society of Mechatronics), the International Mechatronics Society, the International Lasers Club.

Fourth Author Spanu Alina was born in Bucharest, Romania, on November 29, 1958. She graduated from Politechnica University of Bucharest, Faculty of Fine Mechanics and Doctoral School of Faculty of Mechanical Engineering and Mechatronics, receiving the $\mathrm{PhD}$ engineer. Eng. degree.

She published: Grafica 3D asistata de calculator, editor Printech, Bucharest in 2016; Programarea calculatoarelor - notiuni de baza si aplicatii, editor Printech, Bucharest in 2015

Dr. Spanu Alina is a member of SROMECA (Romanian Society of Mechatronics) and a member of The Romanian Robotics Society.

Doina Cioboata was born in Bucharest, Romania, on April 23, 1960. She graduated from Politechnica University of Bucharest, Faculty of Fine Mechanics and Doctoral School of Faculty of Mechanical Engineering and Mechatronics, receiving the $\mathrm{PhD}$ engineer. Eng. degree.

She is a reviewer for Mechatronics Journal at Elsevier Editorial System (EES). Some relevant publications: Lathe machining in the era of industry 4.0: Remanufactured lathe with integrated measurement system for CNC generation of the rolling surfaces for railway wheels, chapter published in book "Product lifecycle management for digital transformation of industries,” Dr. Doina Cioboata is a member of SROMECA (Romanian Society of Mechatronics) and a member of AGIR (Romanian General Association of Engineers) 